\title{
Does Music Help to Stay Focus on the Road?
}

\author{
MAI MARIAM MOHAMED AMINUDDIN ${ }^{1,}$, HASLINAH MODH NASIR ${ }^{2}$ \\ ${ }^{1}$ Centre for Telecommunication Research \& Innovation (CeTRI), \\ Fakulti Kejuruteraan Elektronik \& Kejuruteraan Komputer (FKEKK), \\ ${ }^{2}$ Fakulti Teknologi Kejuruteraan Elektrik \& Elektronik (FTKEE). \\ ${ }^{1,2}$ Universiti Teknikal Malaysia Melaka (UTeM). \\ MALAYSIA
}

\begin{abstract}
Attention in the physiological definition in one of several simultaneous occurrences of ideas takes ownership of the mind which means removing certain stuff to cope efficiently with others. Particular attention is required in driving in order to maintain track of the driver's vigilance to prevent the road accident. In this study, the driver's attention is analyzed by their driving performance from both the amplitude and accident rating of Electroencephalographic (EEG). The subjects were stimulated with radio talk, instrumental music and no sound (silent) in three separate recordings. It was found that drivers encounter much fewer accidents while listening to the radio talk compared to the music and worse driving score when driving in silence. This finding could be used as a foundation to develop tips or methodology to avoid the attention deficit while driving.
\end{abstract}

Key-Words: - attention deficit, music, erp, driving Attention deficit, Music, Radio, EEG, ERP, Driving, Drowsiness

Received: December 5, 2019. Revised: April 28, 2020. Accepted: May 1, 2020. Published: June 3, 2020.

\section{Introduction}

Accidents involving road traffic lead to injuries and fatalities that affect people, families and communities. It places a burden on the healthcare delivery system by occupying restricted hospital beds and using funds, as well as resulting in loss of productivity and earnings, with social and economic implications. From the year 2007 to 2011, Malaysia loses more than RM10 Million owing to road accidents. Statistics and study from the Malaysian Institute of Road Safety Research (MIROS) recorded 7,000 fatalities each year as a result of road accidents and ranked third among other death causes [1]. Malaysia, behind Thailand and Vietnam, has the third-largest death rate from road traffic accidents in Asia and ASEAN in 2016 [2].

A research by the University of Bordeaux in France revealed that 52 percent of the nearly 1000 drivers wounded in an accident reported drifting attention before their vehicles crashed [3]. Scientists say the issue that is also recognized as the syndrome of the white line occurs when those behind the wheel begin to dream or get caught up on the radio. This study is essential, particularly in Malaysia, as road accident increases due to absence of alertness while driving. [4]. Drivers generally listen to music to overcome boredom and stay awake, particularly if they are traveling alone. However, in their melody and lyrics, music has elements of repetition [5]. Repetition is the finest element that causes a deficit of attention. Based on prior studies [6] and [7], important decreases in electrical evoked (erp) potential (Erp is an electrical potential recorded from a human or other animal's nervous system following stimulus presentation, reaction).

Thus, driver electroencephalographic (EEG) a nd driving score from the simulator are analyzed. Concerning EEG, based on [8] N170 wave element is the best to analyze to evaluate driving attention while listening to the music and radio talk as well as silent stimulation, respectively. The results could be useful in maintaining their safety on the highway for the long-distance traveler.

\section{Methodology}

This experiment was attended by a total of 15 participants aged between 18 and 25 years with a valid driving license. All volunteered are students of Universiti Teknikal Malaysia Melaka. Before participating in the experiment, all participants signed informed consent and confirmed in healthy and fresh conditions to ensure no ot her influence except natural attention loss if occur. 
The experiment setup is shown in Fig.1. This experiment uses a driving simulator Carnetsoft. In a semi-circle, three monitors were arranged to offer a $3-\mathrm{D}$ visual. The driving simulator has a periodic steering wheel size, clutch-petrol-brake pedal, gear stick and signal pedal. The Carnetsoft driving simulator records the driving errors and accidents and behavior of subject participant as shown in Fig. 2. The EEG recording environment comprises a BIOPAC Inc biosignal amplifier scheme, MP150 EEG 100C and computer software (Acknowledge 4.2) as well as a surveillance device. At $500 \mathrm{~Hz}$, the EEG was sampled. The electrodes $(\mathrm{Ag} / \mathrm{AgCl})$, the upper lip (adverse electrode) and the vertex $(\mathrm{Cz})$ for grounding are positioned on the left and right occipital. The recording takes place in a light-off soundproof space. This is to prevent noise from lighting while driving and visual disruption.

Simulations had 3 components. Each portion had a break of about 25 minutes and 5 minutes. A less road traffic scenario was performed on the monitor in all areas.

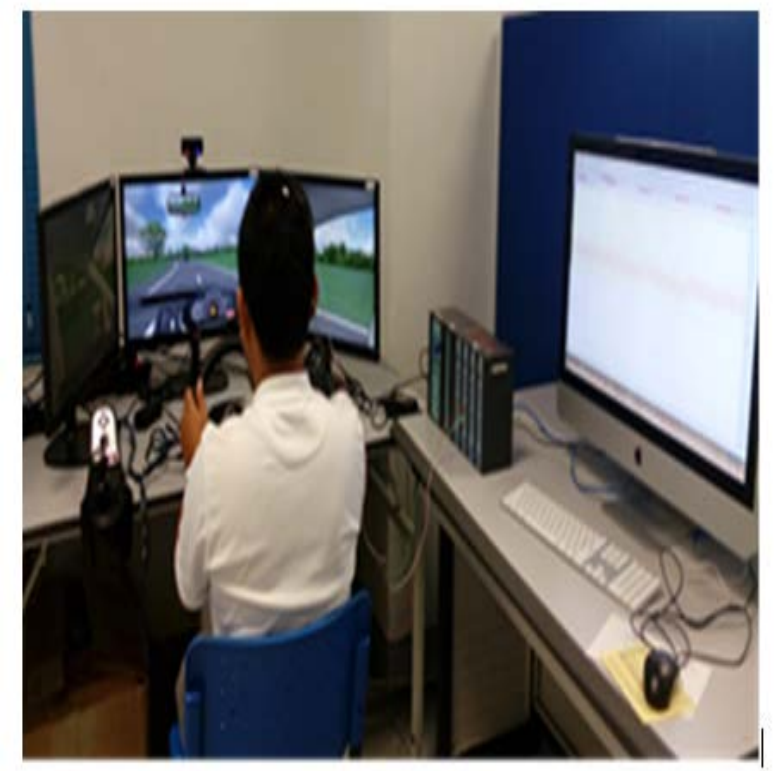

Fig. 1. Driving simulator and EEG recording setup

In first part, no noise (control information) was triggered to the respondents. Except for traffic and vehicle noise, they drove in' quiet' condition. In the second part, participants drove through a headphone with music playing. The music is their favorite music of their own. Any instrumental music of their choice. In the last portion, a talk radio program replaces the music (deejay chatting with the radio caller or the guest).

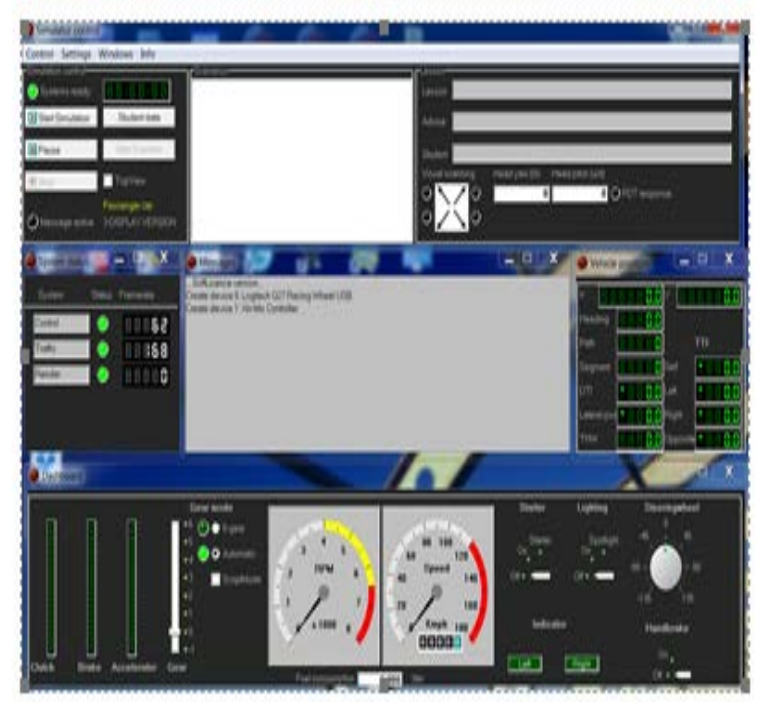

Fig. 2. Driving simulator interface that recorded all performances of the driver

The EEGs are filtered with a digital bandpass filter $(1-30 \mathrm{~Hz})$ to achieve active and focused alpha and beta waves. Using threshold detection (amplitude greater than $50 \mu \mathrm{V}$ ), sweeps containing artifacts were dismissed. At each post-stimulus of $1 \mathrm{~s}$, they were then segmentized. Each participant received at least 500 responses from the recording 


\section{Results and Discussion}

Grand averaged results of all 15 participants are presented in respective stimulation types. Fig. 3, Fig. 4 and Fig. 5 show the amplitude of N170 wave over responses for all stimulations respectively. The amplitudes seem to have noises, but it is not. Noises are already discarded by using the averaging technique. EEG signal is very sensitive, and the scale is in microvolt hence the changing of amplitude between immediate responses looks big. However, overall, the pattern of amplitude decrement can be seen clearly as in $F$ ig. 3. It shows the grand averaged results of silent stimulation.

It is observed that the amplitude of the N10 wave decreases over time. As expected, for music stimulation as shown in Fig. 4, a similar decrement of N170 amplitude is found in all subjects. However, for the radio talk stimulation, see Fig. 5, the amplitude of the N170 wave is almost constant over responses. This is consistent with finding by Jonsson and Dahlback [9] where their assessment found that the combination of submissive and dominant speech helps driver performance.

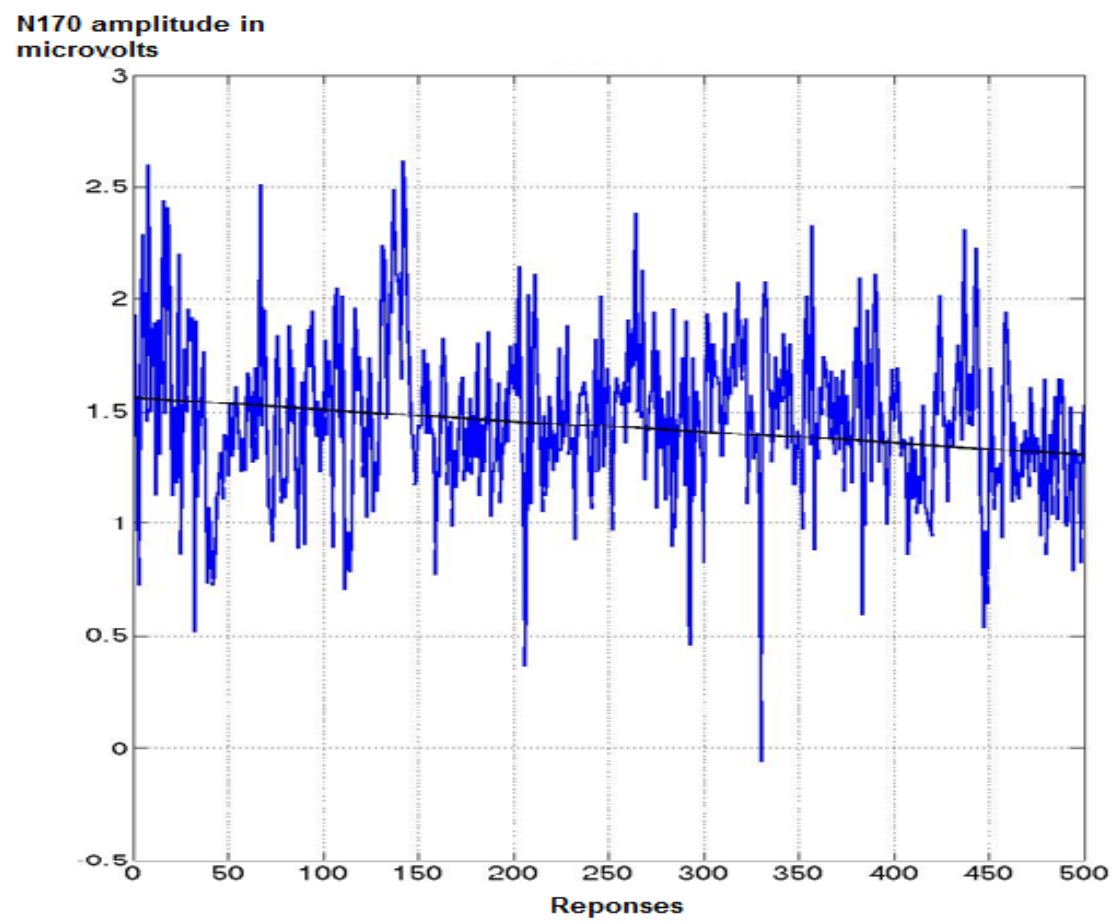

Fig. 3. Grand averaged of all participants for silent stimulation. 


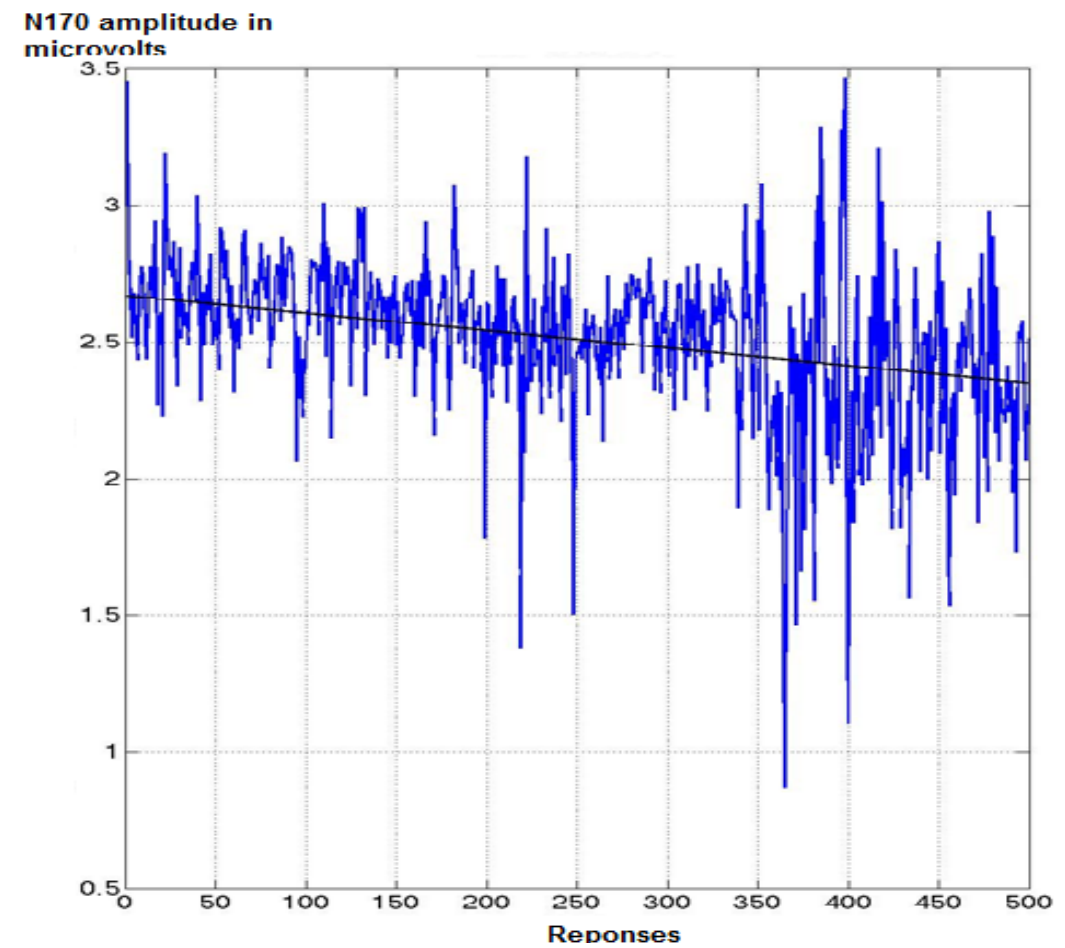

Fig. 4. Grand averaged of all participants for silent stimulation.

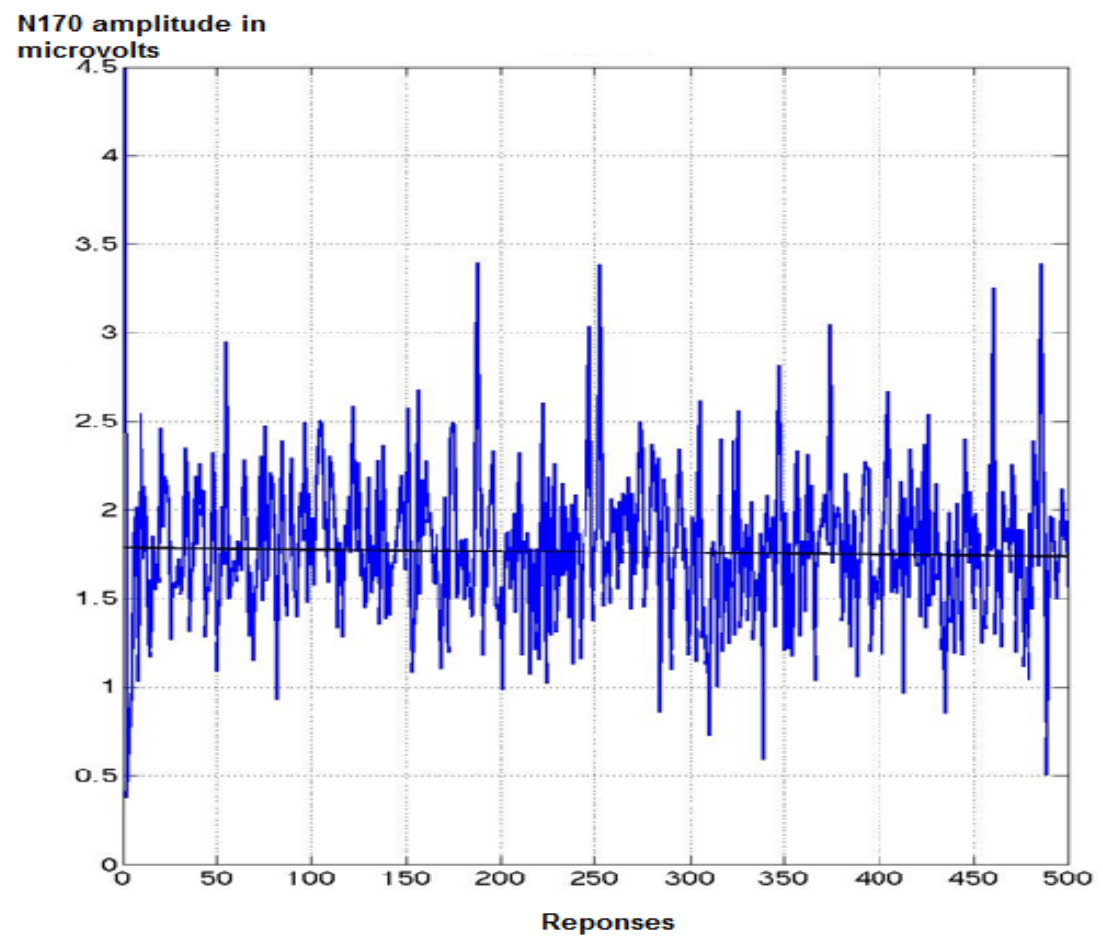

Fig. 5. Grand averaged of all participants for radio talk stimulation. 
TABLE 1: Grand averaged results of all participants for driving score.

\begin{tabular}{|c|c|c|}
\hline Stimulus & \% Warning & \% Accident \\
\hline Silent & $25.0 \%$ & $65.6 \%$ \\
\hline Music & $35.0 \%$ & $49.0 \%$ \\
\hline Radio talk & $4.3 \%$ & $7.7 \%$ \\
\hline
\end{tabular}

From the driving score results, as shown in Table 1, the average of warning and accident percentage are higher when the driver listens to music and in silent condition. Very few warnings and accidents were found when the driver listen to radio talk. These suggested that the driver-focused more on the road if they listen to radio talk compared to when listening to music.

Repetition is detected in music from all over the world [10]. A simple "strophic" pattern is evident in much music, in which a single sentence or phrase is repeated over and over again. When sung, the use of different words is usual for successive repetitions, as is the case with strophic lines. It is also common, however, to hear the same words used with every repetition Based on the findings, it is highly suggested that music is not the best stimulant to overcome boredom and avoid getting drowsiness while driving. Radio talk has up and down tones and pitches which give deviant in a strain of stimulation and block the occurrence of habituation (attention deficit) to the stimulus.

\section{Conclusion}

As disclosed in the outcome and discussion section, this article showed that listening to the radio talk while driving generally allows driving efficiency to be maintained or increased compared to those without listening to it (no stimulation) and listening to music. Hence, it's a nice diversion to listen to radio talk program to maintain the driver's mind on the highway.

\section{Acknowledgement}

The authors are grateful for financial support received through the FRGS research grant (FRGS/1/2017/TK08/FKEKK-

CETRI/F00338) from the Ministry of Higher
Education Malaysia. Thank you very much for the support of Universiti Teknikal Malaysia Melaka.

\section{References:}

[1] "Globus Status Report on Road Safety 2018: Summary," World Health Organization, Geneva, 2018.

[2] A. Abidin, S. Faudzi, F. Lamin and A. Manap, "MIROS Crash Investigation and Reconstruction Annual Statistical Report, 2007-2011," 2012.

[3] M. Taylor, "The Driving Habit You Need to Break," Prevention, 2012.

[4] J. He, E. Becic, Y. C. Lee and J. McCarley, "'Mind Wandering Behind the Wheel:Performance and Oculomotor Correlates. Human Factors," The Journal of the Human Factors and Ergonomics Society, vol. 53, no. 1, pp. 13-21, 2011.

[5] B. \&. Saker, "Music: In Theory and Practice," vol. 1, no. 7, 2003.

[6] M.M.M. Aminuddin and I. Mustaffa, "The effect of sound levels on attention deficit," 2013 International Conference on Instrumentation, Communication, Information Technology and Biomedical Engineering,, pp. 1-4, 2013.

[7] M.M.M. Aminuddin, H. Nasir, M. Othman and I. Mustaffa, "“Objective Verification of Focus," 2015 International Symposium on Technology Management and Emerging Technologies, pp. 49-52, 2015.

[8] H. Nasir, M.M.M. Aminuddin, N. Brahin and I. Mustaffa, "Event Related Potential N100 Vs N170 Wave Results Comparison On Driving Alertness," Journal of Engineering Science and Technology, vol. 14, no. 3, pp. $1150-1160$, 2019.

[9] I. Jonsson and N. Dahlback, "Driving with a Speech Interaction System: Effect of Personality on Performance and Attitude of Driver in Human-Computer Interaction. Advanced Interaction Modalities and Techniques:," in 16th International Conference, HCI International 2014, Heraklion, Crete, Greece, 2014.

[10] B. Nettl. 2005. The Study of Ethnomusicology: Thirty-One Issues and Concepts. Urbana: University of Illinois Press 